\title{
Supplementary Material: Colluvial deposits as a possible weathering reservoir in uplifting mountains
}

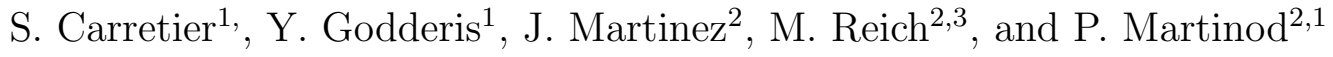 \\ ${ }^{1}$ GET, IRD, CNRS, CNES, OMP, UPS, Université de Toulouse, 14 avenue E. \\ Belin, F-31400, Toulouse, France \\ ${ }^{2}$ Department of Geology, FCFM, Universidad de Chile, Santiago, Chile \\ ${ }^{3}$ Andean Geothermal Center of Excellence (CEGA), FCFM, Universidad de \\ Chile, Santiago.
}

July 21, 2017

\section{Non-dimensionalisation}

In the main manuscript we developed the formulae for the erosion-sedimentation mass balance only. Here we give the whole set of non-dimensional equations including in situ regolith

thickness and clast weathering.

\section{Erosion-sedimentation mass balance}

On a cell, the change in elevation obeys

elev. change $=$ river eros. + river depos. - hillslope eros. + hillslope depos. - lateral eros. + uplift

$$
\frac{\partial z}{\partial t}=-K q^{m} S^{n}+\frac{q_{s r}}{\xi q}-\kappa S+\frac{q_{s h}}{\frac{d x}{1-\left(S / S_{c}\right)^{2}}}-\frac{d q_{s l}}{d x}+U
$$

Using these scaling factors:

$H$ mountain height,

$L$ mountain width,

$P$ precipitacion rate,

$U$ uplift rate,

non-dimensional variables (with a star) are defined by:

$q=q_{*} P L, q_{s r}=q_{s r *} U L, q_{s h}=q_{s h *} U L, q_{s l}=q_{s l *} U L, S=S_{*} \frac{H}{L}, d x=d x_{*} L, z=z_{*} H$, $t=t_{*} \frac{H}{U}$,

so that Equation 1 becomes: 


$$
\frac{\partial z_{*}}{\partial t_{*}}=-N_{\text {riv }} q_{*}^{m} S_{*}^{n}+N_{\text {depo }} \frac{q_{s r *}}{q_{*}}-N_{\text {hill }} S_{*}+\frac{q_{s h *}}{\frac{d x_{*}}{1-\left(S_{*} / S_{c *}\right)^{2}}}-\frac{d q_{s l *}}{d x_{*}}+1
$$

with the following non-dimensional numbers:

Rivers erosion: $N_{\text {riv }}=K U^{-1} P^{m} L^{m-n} H^{n}$

Rivers sedimentation: $N_{\text {depo }}=\xi^{-1} P^{-1}$

Hillslope erosion: $N_{\text {hill }}=\kappa H U^{-1} L^{-1}$

Other non-dimensional numbers include the slope threshold $S_{c}$ and proportionality factor $\alpha$ in the lateral erosion law.

A similarity is expected between the numerical experiments sharing identical values of $N_{\text {riv }}, N_{\text {depo }}, N_{\text {hill }}, S_{c}$ and $\alpha$.

With $m=0.5$ and $n=1$ (Whipple and Tucker, 1999) the non-dimensional numbers become:

Rivers erosion: $N_{\text {riv }}=K U^{-1} P^{0.5} L^{-0.5} \mathrm{H}$

Rivers sedimentation: $N_{\text {depo }}=\xi^{-1} P^{-1}$

Hillslope erosion: $N_{\text {hill }}=\kappa H U^{-1} L^{-1}$

\section{Regolith production}

The variation in the regolith thickness is the sum of the regolith production rate, erosion and deposition rates by the river and hillslope processes:

$$
\frac{\partial B}{\partial t}=w-K q^{m} S^{n}+\frac{q_{s}}{\xi q}-\kappa S+\frac{q_{s}}{\frac{d x}{1-\left(S / S_{c}\right)^{2}}}-\frac{d q_{s l}}{d x}
$$

Using the maximum regolith formation rate $w_{o p}$ (for optimum) as a scaling parameter for $w$, and the same scalings as for equation 2 we obtain

$$
\frac{\partial B_{*}}{\partial t_{*}}=N_{\text {reg }} w_{*}-N_{\text {riv }} q_{*}^{m} S_{*}^{n}+N_{\text {depo }} \frac{q_{s r *}}{q_{*}}-N_{\text {hill }} S_{*}+\frac{q_{s h *}}{\frac{d x_{*}}{1-\left(S_{*} / S_{c *}\right)^{2}}}-\frac{d q_{s l *}}{d x_{*}}
$$

where the non-dimensional number $N_{r e g}=\frac{w_{o p}}{U}$ determines whether or not regolith exists at dynamic equilibrium. $N_{\text {reg }}>1$ produces a regolith-covered mountain, whereas $N_{\text {reg }}<1$ leads to a bare-bedrock mountain (see Carretier et al., 2014, for details).

\section{Clast weathering}

The rate of mineral volume decrease is

$$
\frac{\partial v_{m}}{\partial t}=-w_{m}
$$

Using the following equation for $w_{m}$ 


$$
w_{m}=\frac{P}{P_{\mathrm{O}}}\left[V_{m} \lambda 4 \pi r_{m}^{2} k_{m} e^{E_{a}\left(\frac{1}{R 298.15}-\frac{1}{R T}\right)}\right]
$$

equation 5 can be written as

$$
\frac{\partial v_{m}}{\partial t}=-\frac{1}{\tau_{m}} v_{m}
$$

where the characteristic time scale for mineral dissolution is

$$
\tau_{m}=\frac{r_{m}}{3 \frac{P}{P_{\mathrm{O}}} V_{m} \lambda k_{m} e^{E_{a}\left(\frac{1}{R 298.15}-\frac{1}{R T}\right)}}
$$

A characteristic time scale for the mineral residence in the regolith on the hillslopes at dynamic equilibrium $(\epsilon=U)$ is $\tau_{r}=\frac{B_{o}}{U}$ (e.g. Granger et al., 1996), where $B_{o}$ is the equilibrium regolith thickness. It is not easy to derive $B_{o}$ from Equation 3. We simplify it by considering erosion only and by neglecting the hump in the regolith production law $\left(k_{1}=0\right)$. At dynamic equilibrium, $\epsilon=U$ and we obtain:

$$
B_{o} \sim d_{1} \ln \left(\frac{w_{o}}{U}\right)
$$

where $w_{o}$ represents the kinetic dependence of the regolith production law given by

$$
w_{o}=k_{\mathrm{w}} \frac{P}{P_{\mathrm{O}}}\left[e^{\frac{-E_{\mathrm{a}}}{R}\left(\frac{1}{T}-\frac{1}{T_{\mathrm{O}}}\right)}\right]
$$

Dividing $\tau_{r}$ by $\tau_{m}$, we obtain a non-dimensional number

$$
N_{\text {clast }}=3 \frac{P}{P_{\mathrm{O}}} d_{1} \ln \left(\frac{w_{o}}{U}\right) V_{m} \lambda k_{m} e^{E_{a}\left(\frac{1}{R 298.15}-\frac{1}{R T}\right)} r_{m}^{-1} U^{-1}
$$

This Damköholer number indicates the weathering grade of a clast leaving the hillslopes. When $N_{\text {clast }}$ is large, a clast leaving the regolith is very depleted, while it remains fresh if $N_{\text {clast }}$ is small. The first situation has been called a "supply" or "transport" or "erosion" limited weathering (e.g. Dixon et al., 2009). The second situation has been called a "kinetically" limited regime.

\section{Illustration of the similarity of the experiments}

The similarity between the numerical experiments with different parameters but sharing the same non-dimensional numbers is illustrated by Figure S1 in the case where the mountain is covered by regolith at dynamic equilibrium $\left(N_{r e g}>1\right)$ and the case where no regolith remains $\left(N_{\text {reg }}<1\right)$. 


\begin{tabular}{|ll|}
\hline$N_{\text {reg }}=\frac{w_{o p}}{U}$ & regolith production efficiency \\
$N_{\text {riv }}=K U^{-1} P^{0.5} L^{-0.5} H$ & river erosion efficiency \\
$N_{\text {depo }}=\xi^{-1} P^{-1}$ & river deposition efficiency \\
$N_{\text {hill }}=\kappa H U^{-1} L^{-1}$ & hillslope erosion efficiency \\
$S_{c}$ & hillslope non-deposition efficiency \\
$\alpha$ & lateral erosion efficiency \\
$N_{\text {clast }}=3 P d_{1} \ln \left(\frac{w_{o}}{U}\right) V_{m} \lambda k_{m} e^{E_{a}\left(\frac{1}{R 298.15}-\frac{1}{R T}\right)} r_{m}^{-1} U^{-1}$ & clast weathering efficiency \\
& (Damköholer number) \\
\hline
\end{tabular}

Tab. S1: Synthesis of non-dimensional numbers.

In the first case, the regolith production rate is large enough to form and maintain a regolith even when the erosion rate reaches the uplift rate value, so that $N_{r e g}>1$. We compare two sets of parameters indicated in Figure S1. The different parameters are the erosion coefficient parameters, uplift rate, precipitation rate, mountain width, and clasts (albite mineral) size. The regolith production law is kept the same in both cases. Five thousand clasts are seeded between 0 and $4 \mathrm{~m}$ at the beginning, and then recycled. Note that we impose a constant temperature and precipitation rate with time and elevation, so that the regolith production law is the same everywhere in the mountain. Despite different evolution times and magnitudes of relief, erosion and weathering fluxes, both sets of parameters lead to the same evolution once these variables are normalised. In particular, the ratio between the regolith residence time and mineral dissolution time $\left(N_{\text {clast }}\right)$ is the same in both cases. This similitude allows the weathering outflux to evolve in the same way, i.e. to increase regularly with the erosion rate. This situation corresponds to the "erosion" or "supply" limited regime.

In the second case, the regolith production rate is much lower, so that the regolith production rate does not keep pace with the increasing erosion rate (Figure S1). Thus, the regolith developed in the early stage of the mountain erosion finally disappears (see also Carretier et al., 2014). This corresponds to $N_{\text {reg }}<1$. Note that in this case, there is no regolith, so $N_{\text {clast }}$ is not defined. This situation corresponds to the "kinetically" limited regime.

This analysis has limitations when the weathering varies with the elevation. For example, the cooling of the surface temperature imposed by the mountain uplift decreases the regolith production rate through time. This decrease will be more pronounced in high mountains than in low mountains. During the rise of high mountains, the initial regolith that formed at low (warm) elevations may rapidly disappear. On the contrary it may continue to cover the low mountains. The weathering outflux will evolve differently in both cases. In these cases, $N_{\text {clast }}$ and $N_{\text {reg }}$ are calculated using the temperature and precipitation at mid-elevation of the final topography.

\section{Pedon scale: Comparison with the data for the Santa Cruz terraces data (White et al., 2008)}

Before exploring the weathering outflux at the mountain scale, we tested the model at the pedon scale, using the data of four uplifted marine terraces of Santa Cruz, California, studied by White et al. White et al. (2008). These authors obtained depth profiles of the resid- 
A-

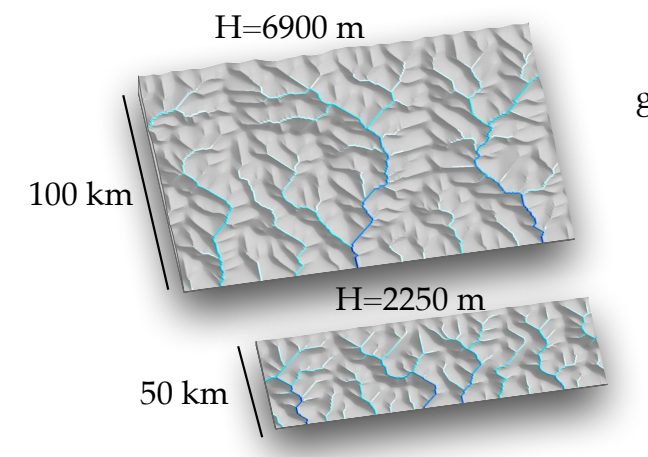

$$
\begin{gathered}
\text { geometry in } \\
\text { a and c }
\end{gathered}
$$

\section{geometry in}

$b$ and $d$

B-

a

$\begin{array}{ll}\mathrm{U}=1 \mathrm{~mm} / \mathrm{a} & \mathrm{U}=0.2 \mathrm{~mm} / \mathrm{a} \\ \mathrm{P}=1 \mathrm{~mm} / \mathrm{a} & \mathrm{P}=0.2 \mathrm{~mm} / \mathrm{a} \\ \mathrm{K}=2.5 \mathrm{e}-4 \mathrm{a}-0.5 & \mathrm{~K}=3 \mathrm{e}-4 \mathrm{a}-0.5 \\ \kappa=1 \mathrm{e}-4 \mathrm{~m} / \mathrm{a} & \kappa=4 \mathrm{e}-5 \mathrm{~m} / \mathrm{a} \\ \zeta=0.1 \mathrm{a} / \mathrm{m} & \zeta=0.5 \mathrm{a} / \mathrm{m} \\ \lambda=160 & \lambda=400 \\ \mathrm{r}_{\mathrm{m}}=1 \mathrm{~mm} & \mathrm{r}_{\mathrm{m}}=2.5 \mathrm{~mm} \\ \mathrm{w}_{\mathrm{O}}=3 \mathrm{~mm} / \mathrm{a} & \mathrm{w}_{\mathrm{O}}=0.6 \mathrm{~mm} / \mathrm{a}\end{array}$

C-

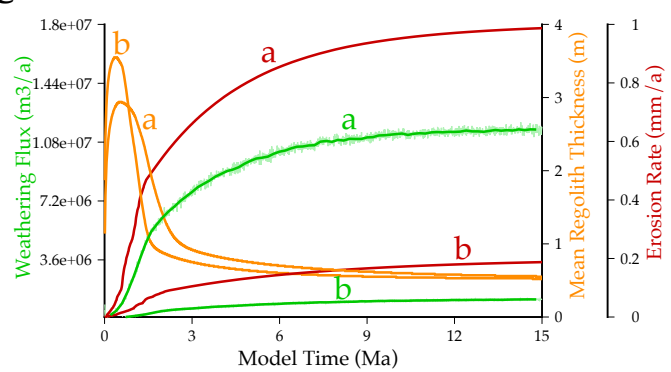

D-

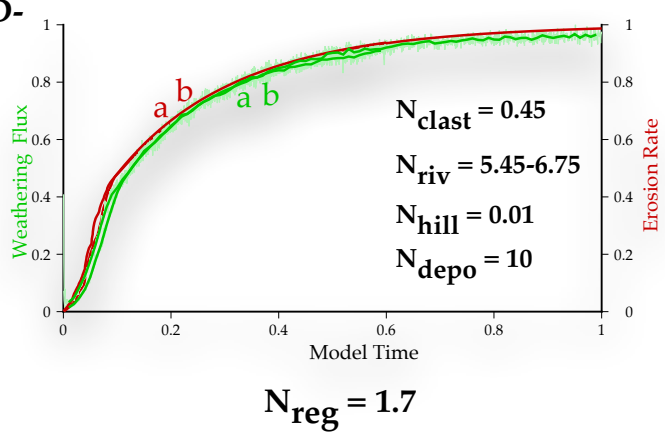

C

$\mathrm{U}=1 \mathrm{~mm} / \mathrm{a}$

$\mathrm{P}=1 \mathrm{~mm} / \mathrm{a}$

$\mathrm{K}=2.5 \mathrm{e}-4 \mathrm{a}-0.5$

$\kappa=1 \mathrm{e}-4 \mathrm{~m} / \mathrm{a}$

$\zeta=0.1 \mathrm{a} / \mathrm{m}$

$\lambda=160$

$\mathrm{r}_{\mathrm{m}}=1 \mathrm{~mm}$

$\mathrm{w}_{\mathrm{O}}=0.5 \mathrm{~mm} / \mathrm{a}$

E-

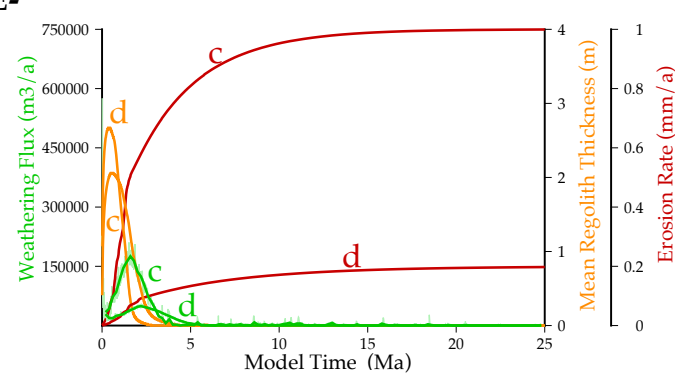

$\mathrm{U}=0.2 \mathrm{~mm} / \mathrm{a}$

$\mathrm{P}=0.2 \mathrm{~mm} / \mathrm{a}$

$\kappa=4 \mathrm{e}-5 \mathrm{~m} / \mathrm{a}$

$\zeta=0.5 \mathrm{a} / \mathrm{m}$

$\lambda=400$

$\mathrm{r}_{\mathrm{m}}=2.5 \mathrm{~mm}$

$\mathrm{w}_{\mathrm{O}}=0.1 \mathrm{~mm} / \mathrm{a}$
F-

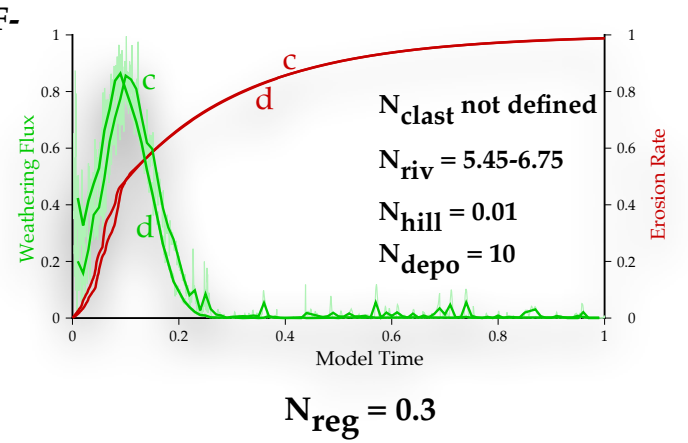

Fig. S1: Illustration of the similarities between some experiments sharing the same nondimensional numbers as in Table S1 but with different mountain widths, uplift and precipitation rates, clast radiuses, erosion and weathering parameters. (A)- Topography and maximum elevation at steady-state for models a-c and b-d. (B)- Parameters used for each experiment. Models a and b share the same non-dimensional numbers as do models $\mathrm{c}$ and d. (C)- Evolutions of the mean regolith thickness, erosion rate, weathering rate in a and b. (D)- Similarity between models a and b for which the time was divided by the time to reach steady-state, and the erosion and weathering rates by their maximum value. (E)- Same as (C)- for models c and d. (F)- Same as (D)- for models c and d. $N_{\text {reg }}>1$ (models a-b) means that the regolith covers the mountain even at a large erosion rate, which is not the case for models c and d for which $N_{\text {reg }}<1$. 


\begin{tabular}{|lllll|}
\hline Terrace & age $(\mathrm{ka})$ & $w_{o}\left(\mathrm{~m} \mathrm{a}^{-1}\right)$ & $\begin{array}{l}k_{m} e^{E_{a}\left(\frac{1}{R 298.15}-\frac{1}{R T}\right)} \\
\left(\mathrm{mol} \mathrm{m}^{-2} \mathrm{~s}^{-1}\right)\end{array}$ & $r_{m}(\mathrm{~m})$ \\
\hline SCT1 & 65 & $3.85 \mathrm{E}-005$ & $8.00 \mathrm{E}-016$ & $1.80 \mathrm{E}-004$ \\
SCT2 & 90 & $5.44 \mathrm{E}-005$ & $1.40 \mathrm{E}-015$ & $1.45 \mathrm{E}-004$ \\
SCT3 & 137 & $5.34 \mathrm{E}-005$ & $8.00 \mathrm{E}-016$ & $1.23 \mathrm{E}-004$ \\
SCT5 & 226 & $3.64 \mathrm{E}-005$ & $4.80 \mathrm{E}-016$ & $9.50 \mathrm{E}-005$ \\
\hline
\end{tabular}

Tab. S2: Cidre parameters used to model the Santa Cruz depletion profiles (Figure S2)

ual amount of albite showing increasing depletion with increasing terrace age. White et al. White et al. (2008) applied a transport-reactive model including the water flow, reaction rate constant for each mineral, reactive surface area based on the spherical minerals and the roughness coefficient $\lambda$, mineral solubility, thermodynamic disequilibrium between the rock and fluid. Their modelled profiles for the residual amount of albite is reproduced in Figure S2A.

In order to model these profiles with Cidre, we started with clasts of albite located every $10 \mathrm{~cm}$ below the surface. Their initial radius is from White et al. (2008). We use the reaction rate constant estimated by White et al. (2008) for albite and each terrace, and the same $\lambda=160$. We impose a constant regolith production rate calculated by White et al. (2008) for each terrace (Table S2). The erosion rate is assumed to be zero as in White et al.'s model. Contrary to White et al.'s model, our model does not include the thermodynamic disequilibrium between the rock and fluid (always maximum disequilibrium).

Following White et al. (2008), we calculate the model profile using the parameters determined for one terrace, and we also calculate the profiles for the other terraces predicted by using the same parameters and different ages.

The predicted profiles fit the data relatively well for each terrace. The depletion profiles display angular extremities, differently from White et al.'s model, which shows sigmoid profiles. This difference arises from the assumption that the fluid-rock disequilibrium is always maximum in Cidre (White et al., 2008; Brantley and Lebedeva, 2011).

Both White et al.'s model and the Cidre model show significant misfit for the other terraces when using the parameters calibrated on one of them. This misfit was attributed to time variations in the fluid flow by White et al. (2008). The fit is slightly better for Cidre for the youngest and oldest terraces. For the younger terrace, a significantly lower flow (precipitation) rate was estimated by White et al. (2008) In order to take this drier condition into account In Cidre, we simply use a smaller regolith production rate. 
a-

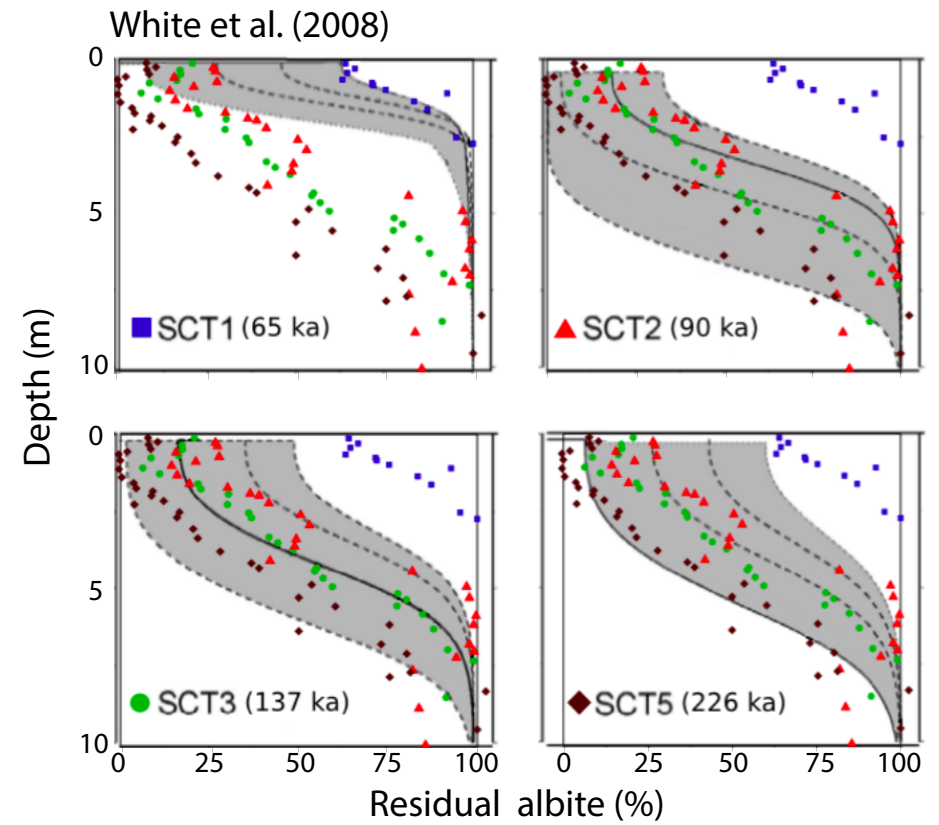

b-

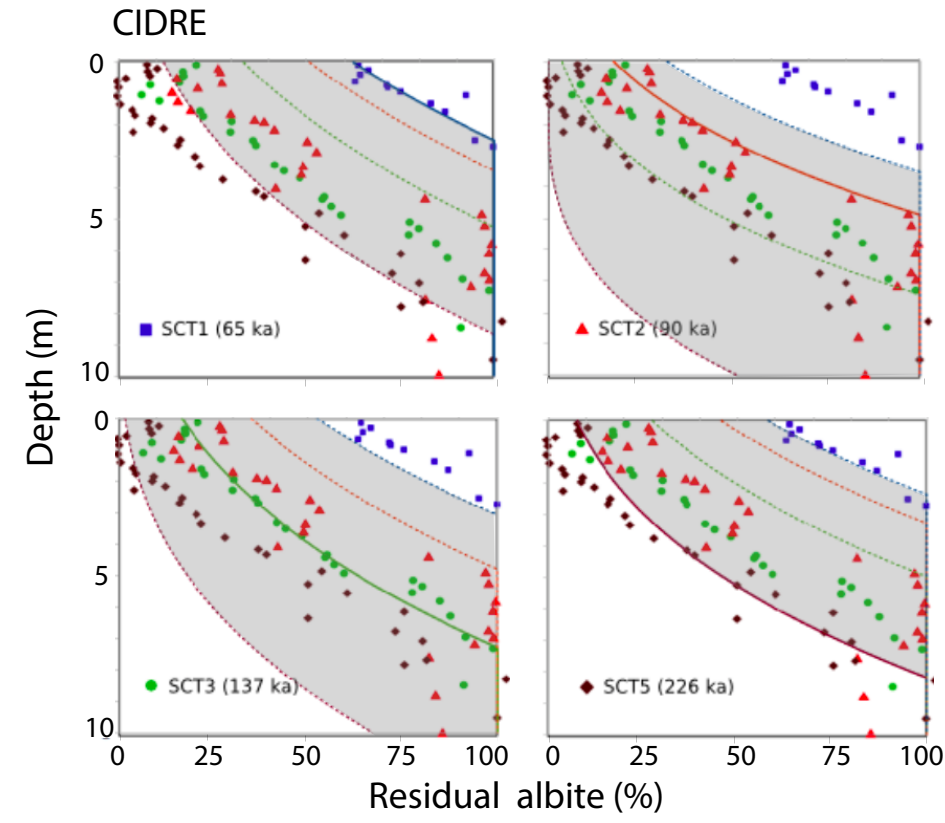

Fig. S2: Test of Cidre at the pedon scale using data from four marine terraces of different ages close to Santa Cruz, California from White et al. (2008). (a-) Depth profiles of the percentage of residual albite and adjusted models of White et al. (2008). For each terrace, the model was adjusted to the corresponding profile (solid lines), and the other profiles that were predicted using the same adjusted parameters and different times (dashed lines) (see details in White et al., 2008). The grey area is the area between the oldest and youngest profiles. Modified from White et al. (2008). (b-) Modelled profiled obtained using Cidre, initially setting albite clasts at depth in the fresh parent rock. 


\section{Complementary Table}

Tab. S3: Synthesis of main model parameters.

\begin{tabular}{|ll|}
\hline$w_{o}\left[\mathrm{LT}^{-1}\right]$ & saprolite production rate of exposed bedrock \\
$k_{w}\left[\mathrm{LT}^{-1}\right]$ & kinetic weathering for exposed bedrock \\
$k_{1}\left[\mathrm{LT}^{-1}\right]$ & factor decreasing the saprolite production rate of exposed bedrock \\
$d_{1}[\mathrm{~L}]$ & parameter controlling the decrease in $w$ at large depth \\
$d_{2}[\mathrm{~L}]$ & parameter controlling the increase in $w$ at shallow depth \\
$T[\theta]$ & temperature at see level \\
\hline$K\left[\mathrm{~T}^{-0.5}\right]$ & river erosion coefficient \\
$\xi\left[\mathrm{TL}^{-1}\right]$ & parameter of the river transport length \\
\hline$\kappa\left[\mathrm{LT}^{-1}\right]$ & diffusion coefficient: m a \\
$S_{c}[1]$ & critical slope for sediment deposition \\
\hline$\alpha[1]$ & factor controlling the lateral erosion \\
\hline$P\left[\mathrm{LT}^{-1}\right]$ & precipitation rate \\
$U\left[\mathrm{LT}^{-1}\right]$ & uplift rate \\
$d x[\mathrm{~L}]$ & cell size \\
\hline$r[\mathrm{~L}]$ & clast radius \\
$V_{m}\left[\mathrm{~L}^{3} \mathrm{~N}^{-1}\right]$ & molar volume of mineral $m$ \\
$k_{m}\left[\mathcal{N} \mathrm{L}^{-2} \mathrm{~T}^{-1}\right]$ & dissolution parameter of mineral $m$ \\
$E_{a}\left[\mathrm{M}^{2} \mathrm{~T}^{-2} \mathcal{N}^{-2}\right]$ & activation energy \\
$\lambda[1]$ & mineral roughness coefficient \\
\hline
\end{tabular}




\section{${ }_{147}$ References}

Brantley, S. and Lebedeva, M.: Learning to Read the Chemistry of Regolith to Understand the Critical Zone, Annu. Rev. Earth Planet. Sci., 39, 387-416, doi:10.1146/annurev-earth040809-152321, 2011.

Carretier, S., Godderis, Y., Delannoy, T., and Rouby, D.: Mean bedrock-to-saprolite conversion and erosion rates during mountain growth and decline, Geomorphology, 209, 29-52, doi:10.1016/j.geomorph.2013.11.025, 2014.

Dixon, J., Heimsath, A., and Amundson, R.: The critical role of climate and saprolite weathering in landscape evolution, Earth Surf. Proc. Land., 34, 1507-1521, doi: 10.1002/esp.1836, 2009.

Granger, D., , Kircher, J., and Finkel, R.: Spatially averaged long-term erosion rates measured from in situ-produced cosmogenic nuclides in alluvial sediment, The Journal of Geology, 104, 249-257, 1996.

Whipple, K. X. and Tucker, G. E.: Dynamics of the stream-power incision model: implication for heigth limits of mountain ranges, landscape response timescales, and research needs, J. Geophys. Res., 104, 17,661-17,674, 1999.

White, A., Schulz, M., Vivit, D., Blum, A., Stonestrom, D., and Anderson, S.: Chemical weathering of a marine terrace chronosequence, Santa Cruz, California I: Interpreting rates and controls based on soil concentration-depth profiles, Geochim. Cosmochim. Acta, 72, $36-68,2008$. 